\title{
Emotions and Emotion Regulation in a Female Couple Undergoing in Vitro Fertilization Treatment
}

\author{
Tracey J. Devonport, Andrew M. Lane \\ University of Wolverhampton, Walsall, UK \\ Email: T.Devonport@wlv.ac.uk
}

Received February $19^{\text {th }}, 2013$; revised March $26^{\text {th }}, 2013$; accepted April $20^{\text {th }}, 2013$

\begin{abstract}
Copyright ( $\subseteq 2013$ Tracey J. Devonport, Andrew M. Lane. This is an open access article distributed under the Creative Commons Attribution License, which permits unrestricted use, distribution, and reproduction in any medium, provided the original work is properly cited.
\end{abstract}

\begin{abstract}
Research indicates that women undergoing In Vitro Fertilization (IVF) experience intense unwanted emotions, and that these emotions may result in the decision to abandon treatment. This case-study explored stressors, emotional responses and emotion regulation strategies of a female couple undergoing IVF procedures over a ten-week period. A mixed-method approach involved participants completing a daily open-ended diary and self-report scales to assess emotions and emotion regulation in relation to partner and self. Diary results indicated both partners experienced frequent stressors resulting from the IVF process, stressors that were intensified by perceptual and financial factors. Participants experienced a range of intense pleasant (e.g., happy, excited) and unpleasant emotions (e.g., depressed, anxious), and sought to down-regulate unpleasant emotions using a range of cognitive, behavioral, and social strategies. Questionnaire data indicated complementary styles of emotion regulation that appeared to help sustain pleasant emotions and down-regulate unpleasant emotions. Future research should test the effectiveness of interventions to help manage unwanted emotional responses to IVF treatment and corresponding regulatory efforts.
\end{abstract}

Keywords: Emotion Regulation; Emotion; In Vitro Fertilization; Coping; Stress

\section{Introduction}

There has been an increase in the number of couples seeking assisted-reproduction treatments among western cultures (Walsh, Collins, Le Du, Walsh, \& Sills, 2009). Assisted reproductive treatment is a general term referring to methods used to achieve pregnancy by artificial or partially artificial means. The fertility treatment "In Vitro Fertilization" (IVF) is expensive, complex and associated with significant side effects (Macklon, Stouffer, Giudice, \& Fauser, 2006). The treatment itself takes between four and six weeks to complete and constitutes a course of hormone therapy to down-regulate the pituitary, followed by ovarian stimulation to develop follicles in the ovary. These follicles produce eggs that are fertilized in vitro to create embryos. As in natural conception, not every embryo implants to become a pregnancy, as such any surplus embryos are frozen so that a subsequent transfer might be attempted if the first attempt fails (Verberg et al., 2008). The treatment itself along with its unpredictable nature/outcomes often presents stressors (Olivius, Friden, Borg, \& Bergh, 2004; Verhaak et al., 2007). Problems can occur at any stage of the IVF process that might lead to undesired outcomes such as the failure to produce viable embryo's, failed implantation, or the couple deciding to abandon IVF (Human Fertilisation and Embryology Authority IVF figures: http://www.hfea.gov.uk/ivf-figures-2006.html).

\section{Emotions Associated with IVF}

Evidence indicates that women undergoing IVF experience intense unwanted emotions such as anxiety and depression (Boivin \& Lancastle, 2009; Schmidt, 2009) and that emotions influence physical and subjective well-being (see Consedine \& Moskowitz, 2007 for a review). Emotions can be functional, for example, the emotions of happiness and excitement can signal to the individual that they are likely to achieve their goal and help maintain desirable behaviors. However, emotions can also be dysfunctional, for example, an individual might be anxious about following medical procedures such as self-injecting, recognising that failure to adhere to these procedures will be detrimental they may choose withdraw from the process. A number of studies have reported that the decision to abandon IVF associates with feeling intense anxiety and depression (Peddie, Van Teijlingen, \& Bhattacharya, 2005; Van den Broeck et al., 2009). Therefore, examination of emotional states and how these emotions are managed among couples going through IVF represents a worthwhile line of enquiry.

\section{Emotion Regulation}

There has been an increase in research on emotion regulation (see Augustine \& Hemenover, 2008; Koole, 2009; Webb, Miles, \& Sheeran, 2012). Emotion regulation is proposed to be an automatic and controlled process that involves the initiation, maintenance and modification of the occurrence, intensity, and duration of feeling states (Eisenberg, Fabes, Guthrie, \& Reiser, 2000; Gross \& Thompson, 2007). Emotion regulation can be distinguished according to whether strategies are targeted toward the person's own feeling states (intra-personal emotion 
regulation) or targeted toward another person's feeling states (inter-personal emotion regulation). Over 400 different emotion regulation strategies have been identified (Augustine \& Hemenover, 2008; Koole, 2009; Webb, Miles et al., 2012), however, little is known about the way in which an individual selects and applies emotion regulation strategies when confronted with potentially stressful situations (Liu, Prati, Perrewé, \& Brymer, 2010; Sheppes, Scheibe, Suri, \& Gross, 2011). By assessing the relationships among individual differences in emotion regulation of self and others (i.e., habitual tendencies), the implications of regulatory behaviors for goal pursuit and healthy adaptation may be better understood (Gross \& John, 2003; Tamir, 2011; Webb, Schweiger Gallo, Miles, Gollwitzer, $\&$ Sheeran, 2012).

The focus of much research has been on self-regulation. Recent research has focused on how emotion regulation occurs in close dyadic relationships (Parkinson \& Simons, 2012). Parkinson and Simons (2012) found that expressing worry may either serve the interpersonal regulation goal of alerting another person to a potential concern or may represent empathic communication. However, this observation assumes that the receiver of the message could decode its meaning, and then initiate appropriate action (Webb, Schweiger et al., 2012). Evidence shows people vary in the extent to which they can accurately identify and detect emotions in others and self, and therefore, the strength of this signal is likely to be influenced by individual differences.

Research has found people initiate interpersonal emotion regulation not only to try to change others emotions, but also their own (Niven, Totterdell, Holman, \& Headley, 2012); that is people initiate strategies to cheer both the agent and themselves up. However, previous research has not examined whether these effects occur among dyads experiencing potentially stressful events. The present study aims to address this gap in the literature. This seems particularly important given the evidence that women experience intense emotions (Peddie, et al., 2005; Van den Broeck et al., 2009) during IVF, suggesting the partner has an important role to play in identifying when such emotional episodes occur and initiating an appropriate regulatory strategy. It is also worth noting that evidence shows that witnessing intense unwanted emotions associates with fatigue (Totterdell, Hershcovis, Niven, Reich, \& Stride, 2012). In the context of a dyad going through IVF, if one partner experiences stressful emotions, this could have negative effects on the other partner. Therefore, attending to each other's emotional state appears to be warranted.

\section{Research Aims}

The aim of the present study was to explore stressors, emotional responses and emotion regulation strategies of a couple undergoing IVF. Lazarus and Lazarus (2006) cautioned that research on emotions requires measures that capture conditions generating emotions and their relational meanings. The use of a longitudinal mixed methods case study of a dyadic relationship could facilitate an examination of emotion states, relational meaning and regulatory behaviors. The value of the case-study lies in capturing real life transactions that might be lost when looking to summarize findings into theoretical propositions and generalizations (Flyvbjerg, 2006; Stake, 1995). Qualitative methods afford the opportunity to analyze and make sense of the personal experiences of individuals (Smith, 2008), allowing an exploration of psychological concepts and the mechanisms underlying them (Bird, Mansell, \& Tai, 2009; Higginson \& Mansell, 2008). Flyvbjerg (2006: p. 228) suggested that case studies are central to learning and scientific development as they provide "the force of example". Case studies may contribute toward a better understanding of the implications of emotions and emotion regulation for goal pursuit and healthy adaptation among self and others. Such examples might be particularly useful for practitioners working around the concepts described.

\section{Method}

\section{Participants}

Participants were a white female couple; Partner 1: Age 32 years; Partner 2; Age 38 years. Partner 2 underwent treatment that followed two failed attempts at Intrauterine Insemination (IUI) and one failed IVF. These treatments had all taken place in the five months preceding the present IVF cycle. It is important to note that the first author was both participant (undergoing treatment) and researcher in the present study. The study of the researcher as a subject of scientific investigation is becoming acceptable in many disciplines including sociology (Denzin, 1997; Lucal, 1999), education (Hayler, 2011) and nursing (Brunner, 2004; Sandelowski, 1994). The researchers adhered to guidelines advocated when undertaking researcher self-enquiry (Denzin, 1997; Denzin \& Lincoln, 2005). First, to facilitate accurate recall both participants independently completed a daily emotion and emotion regulation diary. Second, there was triangulation of data sources (questionnaire and open ended diaries) and content (independent assessment of self and other) to increase trustworthiness. Third, multiple data analysis strategies were implemented and fourth, existing literature was used as a framework to guide analysis and interpretation. In a further attempt to ensure that data interpretation and presentation was objective and reliable, the second author collated all data and was involved in the analysis, presentation and interpretation of results.

\section{Measures}

\section{Emotion}

A six-item measure was used to assess emotions with items selected from the UWIST mood adjectives checklist (Matthews, Jones, \& Chamberlain, 1990). Three items represent pleasant emotions (calm, energetic, \& happy), and three items represent unpleasant emotions (angry, anxious, \& gloomy). Items were rated on a 7-point scale from 1 (not at all) to 7 (a great extent). We calculated a single measure of emotion by subtracting unpleasant emotions from pleasant emotions.

\section{Emotion Regulation of Others and Self (EROS: Niven, Totterdell, Stride, \& Holman, 2011)}

Niven et al. (2011) developed the Emotion Regulation of Others and Self scale (EROS) to assess strategies used to increase pleasant emotions and strategies used to increase unpleasant emotions in others and one self. Niven et al. reported that the EROS scale showed factorial and concurrent validity using confirmatory factor analysis techniques, reporting alpha values greater than .70 . This meets criterion suggested by Tabachnick and Fidell (2001) as demonstrating acceptability. 
Subsequent research has found that the scale cross-validated to a different context (Lane, Beedie, Devonport, \& Stanley, 2011). Examples of items include; "I did something I enjoy to try to improve how I felt" (increase one's own pleasant emotions), "I expressed cynicism to try to make myself feel worse" (increase one's own unpleasant emotions), "I gave someone helpful advice to try to improve how they felt" (increase pleasant emotions in others) and "I told someone about their shortcomings to try to make them feel worse" (increase unpleasant emotions in others). Participants rated items on a 5-point scale where 1 equals "not at all" and 5 equals "a great deal". Participants were informed to rate the frequency of usage rather than evaluate whether each strategy was effective. Alpha coefficients in the present study were greater than .70 .

\section{Open-Ended Daily Emotion and Emotion Regulation Diary}

Expressive writing was used to capture stressors and the emotional experiences of the first author and their partner on a daily basis in the two weeks proceeding, five weeks during and three weeks following the present IVF cycle. This provides rich data for the case study and has been shown to result in significantly better physical and psychological outcomes for participants faced with stressful and emotional events (Baikie \& Wilhelm, 2005). The diary used prompts to encourage expressive reflections concerning stressors, strategies used to manage their own and partner's emotions and situational factors perceived as influencing emotion experiences and regulation.

\section{Procedure}

In the present study, participants rated their emotions and emotion regulation strategies for the previous 24-hour on a daily basis. Participants were e-mailed the survey link as a reminder to complete the scale each morning.

\section{Data Analysis}

Our research sought to explore answers to the following questions: First, is one partner feeling happier than the other? Secondly, is there a difference between how I report feeling to how you think I feel? Third, how does the assessment of my own and partner's emotions relate to strategies used to regulate emotion (in self and partner)? Correlation was used to examine relationships between own and partner's emotions and regulation strategies used.

Qualitative data allowed an in depth review of participants' experiences of IVF including associated stressors, resultant emotional experiences (self and partner) and strategies used to regulate own and partner's emotions. The computer software QSR Nvivo-8 (2009) was used to facilitate the organization of quotes into meaningful categories. A content analysis was performed to generate categories of stressors, emotions and emotion regulation strategies collectively experienced before, during and following the outcome of IVF.

\section{Results}

\section{Quantitative Data}

Descriptive statistics for self-rating of own emotions (how I felt today) and other's rating (how I thought you felt today) are contained in Table 1. We analysed data in terms of three main
Table 1.

Emotional states and emotion regulation strategies in self and partner.

\begin{tabular}{ccccc}
\hline & \multicolumn{2}{c}{ Partner 1 } & \multicolumn{2}{c}{ Partner 2 } \\
\hline & $\mathrm{M}$ & $\mathrm{SD}$ & $\mathrm{M}$ & $\mathrm{SD}$ \\
Own emotion & 4.02 & 1.34 & 3.96 & .82 \\
Partners emotion & 4.47 & 1.24 & 3.72 & 1.10 \\
Increase own pleasant emotion & 1.93 & .58 & 1.26 & .29 \\
Increase other pleasant emotion & 2.08 & .57 & 1.24 & .38 \\
Increase other unpleasant emotion & 1.25 & .00 & 1.27 & .07 \\
\hline
\end{tabular}

questions. First, we examined the question is one partner happier than the other? As Table 1 indicates, there were no significant differences in the intensity of emotional states between each partner $(t=.30, p=.76)$. Second, we examined the question; did one partner perceive that the other partner was happier? Results indicated that partner 1 reported that partner 2 is happier than she is $(t=2.32, p=.024)$, that is, when assessing her own emotional state, she reported that she believed her partner was happier. In contrast, partner 2 reported no significant difference in response to the same question $(t=1.98, p=.065)$. Thirdly, we examined the question did my rating of your emotions differ significantly to your self-rating? Results indicate that partner 1 significantly over-estimated the intensity of partner 2's pleasant emotion $(t=5.52, p<.001)$, that is, she rated her partner to be in a more pleasant mood than partner 2's own self-rating. As Table 1 indicated, participant 1 rated participants 2 emotional state to be an average of 4.47 , which is significantly higher than her self-rating average score of 3.96. By contrast, partner 2 significantly under-estimated the intensity of her partner's pleasant emotions $(t=-2.19, p=<.032)$, that is, she rated her partner's emotions as less happy than her partner's own self-rating. As Table 1 indicated, participant 2 reported a score of 3.72, with partner 1 scoring herself a mean of 4.02.

In terms of strategies used to regulate emotions, results indicated that partner 1 reported using strategies to regulate her partner's emotion significantly more than partner 2 (Mann Whitney $\mathrm{U}=917, p<.001)$. It should be noted that neither participant reported the use of strategies intended to increase their own unpleasant emotions and so this variable was discarded.

Relationships between emotions and emotion regulation strategies are contained in Table 2. For both partners, rating of own emotion correlated with rating of partner's emotion although this relationship was stronger for partner 2. For partner 1, selfrating of the intensity of feeling pleasant emotion correlated positively with strategies intended to increase one's own pleasant emotions and strategies to increase pleasant emotions in one's partner. By contrast, for partner 2, rating of own pleasant emotion inversely correlated with strategies to increase the intensity of pleasant emotion in oneself. In addition, partner 2's rating of partner's pleasant emotion inversely correlated with use of strategies to increase own pleasant emotion and partner's pleasant emotion.

\section{Qualitative Data}

Over the duration of the present IVF cycle, participants collectively recorded 46,262 words of text (partner $1=13,622$, 
partner $2=32,649)$. In order to facilitate the interpretation and presentation of the substantive qualitative data, data will be reported in coding hierarchies that represent the key emergent themes. Direct quotations that represent these themes will also be presented thereby portraying critical IVF moments and emotion regulatory strategies as determined by participants.

\section{Pertinent Stressors}

As Table 3 indicates, participants' perceptions regarding treatment protocols, hospital communication and the availability of ongoing support presented a range of stressors. Stressors were clustered under three related themes, those being hospital, tangible and perceptual stressors. Participants perceived there to be ambiguity in the treatment process as evidenced by participant 2:

When she outlined my treatment from here in it differed from that described by other nurses. This does concern me, whilst I appreciate that it may vary depending on how your body reacts, some of the differences that appear a week apart are alarming. Last week I was told I would not start pessaries until the day of insemination, today I was told I start them tomorrow... I do not understand how there can be such differences and it undermines my confidence in the service.

As a consequence of the treatment process both participants experienced a range of pleasant and unpleasant emotions. Pleasant emotions experienced included overjoyed, excited, relieved, happy, relaxed, calm and optimistic. However, the emotions described were predominantly unpleasant on account of the uncertainty relating to achieving the goal of becoming pregnant and were experienced throughout a great deal of the treatment process. Unpleasant emotions identified by participants included disappointment, depression, worry, fear, anxiety, downhearted, irritable, anger, confused and pressured. In managing these intense emotions, both participants evidenced a range of intra-personal and inter-personal regulation strategies that are presented in Tables $\mathbf{4}$ and $\mathbf{5}$ respectively.

\section{Intra-Personal Emotion Regulation}

Table 4 presents strategies utilized to regulate one's own emotions (intra-personal). The focus of strategies for regulating unpleasant emotions was to attenuate or eliminate unpleasant emotions whereas the intention for strategies for regulating pleasant emotions was to maintain or increase the felt emotion. Strategies could be described as; 1) cognitive (e.g., re-appraisal, positive thinking, and cognitive avoidance), 2) behavioral (e.g., routines, behavioral distractions, or treats) and, 3) social (e.g., seeking support for emotional or informational purposes, sharing positive experiences).

The following excerpt provided by participant 2 evidences intra-personal emotion regulation strategies of positive thinking and putting in perspective when attempting to manage the process of self-injecting:

The thought of pushing a needle into my own skin for its full length (just under an inch) made me anxious and uncomfortable. I thought about positive aspects of my situation to manage my moods and behaviors. I thought about the fact we are trying to have a baby, I thought about people like [states name of a friend] who have to do this for health reasons.

Table 2.

Correlation between emotion and emotion regulation strategies.

\begin{tabular}{|c|c|c|c|c|c|}
\hline Partner & & Partner's emotion & $\begin{array}{l}\text { Increase the intensity of } \\
\text { own pleasant emotions }\end{array}$ & $\begin{array}{l}\text { Increase the intensity of partner's } \\
\text { pleasant emotions }\end{array}$ & $\begin{array}{c}\text { Increase the intensity of partner's } \\
\text { unpleasant emotions }\end{array}$ \\
\hline \multirow[t]{2}{*}{1} & Own emotion & $.29^{*}$ & $.39^{*}$ & $.48^{*}$ & .10 \\
\hline & Partner's emotion & & .16 & .21 & .16 \\
\hline \multirow[t]{2}{*}{2} & Own emotion & $.58^{*}$ & $-.51^{*}$ & -.16 & -.20 \\
\hline & Partner's emotion & & $-.33^{*}$ & $-.33^{*}$ & -.14 \\
\hline
\end{tabular}

Note: ${ }^{*} p<.01$

Table 3.

Stressors associated with IVF.

\begin{tabular}{|c|c|c|}
\hline Raw data example & Higher order theme & General dimension \\
\hline "They are hopeless at guiding us through the process and letting us know what to expect" & Treatment management & \\
\hline $\begin{array}{l}\text { "She sees a bruise and tells me I am injecting on the wrong place, } \\
\text { this is where the other nurse told me to inject" }\end{array}$ & Hospital staff communications & $\begin{array}{l}\text { Hospital } \\
\text { stressors }\end{array}$ \\
\hline $\begin{array}{l}\text { "Others are called in pairs, the female and male partner, I am slightly annoyed that yet again they just } \\
\text { call for me and I have to introduce [partner] again and explain why she is there" }\end{array}$ & Hospital support & \\
\hline "If it's still there they will abort the IVF (no refund of approx $70 \%$ fees)" & Finances & \multirow{2}{*}{$\begin{array}{l}\text { Tangible } \\
\text { stressors }\end{array}$} \\
\hline $\begin{array}{l}\text { "Within the last } 11 \text { months I've spent around five months on IVF treatments and } 8 \text { weeks } \\
\text { waiting to find out if we're pregnant. This has been a huge commitment in terms of time" }\end{array}$ & Time & \\
\hline "I find myself monitoring physical symptoms" & Heightened awareness & \multirow{3}{*}{$\begin{array}{l}\text { Perceptual } \\
\text { stressors }\end{array}$} \\
\hline $\begin{array}{c}\text { "Implantation eve and just not knowing if they will defrost okay and not } \\
\text { wanting any to be damaged makes me anxious" }\end{array}$ & Fears & \\
\hline "I feel totally out of control in this process now" & Perceived control & \\
\hline
\end{tabular}




\section{T. J. DEVONPORT, A. M. LANE}

\section{Inter-Personal Emotion Regulation}

Table 5 presents strategies used to regulate partners emotions (inter-personal). As with intra-personal strategies, the focus of strategies for regulating unpleasant emotions was to attenuate unpleasant emotions whereas the intention of strategies for regulating pleasant emotions was to create, maintain or increase pleasant emotions. It was apparent that where possible, strategies were selected based upon their perceived suitability for the context and to match partners preferences for emotion regulation.
The following excerpts evidence inter-personal emotion regulation strategies selected for their known efficacy in relation to partner preferences or for their perceived suitability for the context in which they were used:

Partner 2: [Partner] does use and respond to humor... If I can make a joke out of something where appropriate it does work.

Partner 1: When I got home from work yesterday I found [Partner] very upset as she's been getting symptoms which may indicate that the IVF hasn't worked. I tried to comfort her; I didn't want her to get too distraught and wanted her to stay

Table 4.

Intra-personal regulation of unpleasant and pleasant emotions resulting from IVF.

\begin{tabular}{|c|c|c|}
\hline Raw data example & Higher order theme & General dimension \\
\hline "I called NHS direct as the internet listed lots of possible reasons and I wanted to be sure" & Seeking support & \multirow{7}{*}{$\begin{array}{c}\text { Regulating } \\
\text { Unpleasant } \\
\text { emotions }\end{array}$} \\
\hline "I try not to think about it and concern myself with it" & Cognitive avoidance/distraction & \\
\hline "I spent the day clearing out my wardrobe for charity and tidying as a distraction" & Behavioral avoidance/distraction & \\
\hline "I felt a little unwell in the evening, and hope it is simply to do with the treatment" & Re-appraisal & \\
\hline "I tried to think of nice things I would do to make myself feel better if this does not work" & Thinking about nice things & \\
\hline "We had agreed to do lunch as a post injection treat" & Treats & \\
\hline "I have a routine that is intended to manage the pessaries which are really not pleasant" & Routines & \\
\hline "We took a photo of the test stick and e-mailed it to our parents and siblings" & Sharing positive experiences & \multirow{4}{*}{$\begin{array}{c}\text { Regulating } \\
\text { Pleasant } \\
\text { emotions }\end{array}$} \\
\hline "Focus on the positives" & Positive thinking & \\
\hline $\begin{array}{l}\text { "I ignored partners mood largely and just got on with things } \\
\text { so I was able to prevent her bad' mood from influencing me in any way" }\end{array}$ & Cognitive avoidance/ distraction & \\
\hline "Spent time reading and chilling out" & Relaxing & \\
\hline
\end{tabular}

Table 5.

Inter-personal regulation of unpleasant and pleasant emotions resulting from IVF.

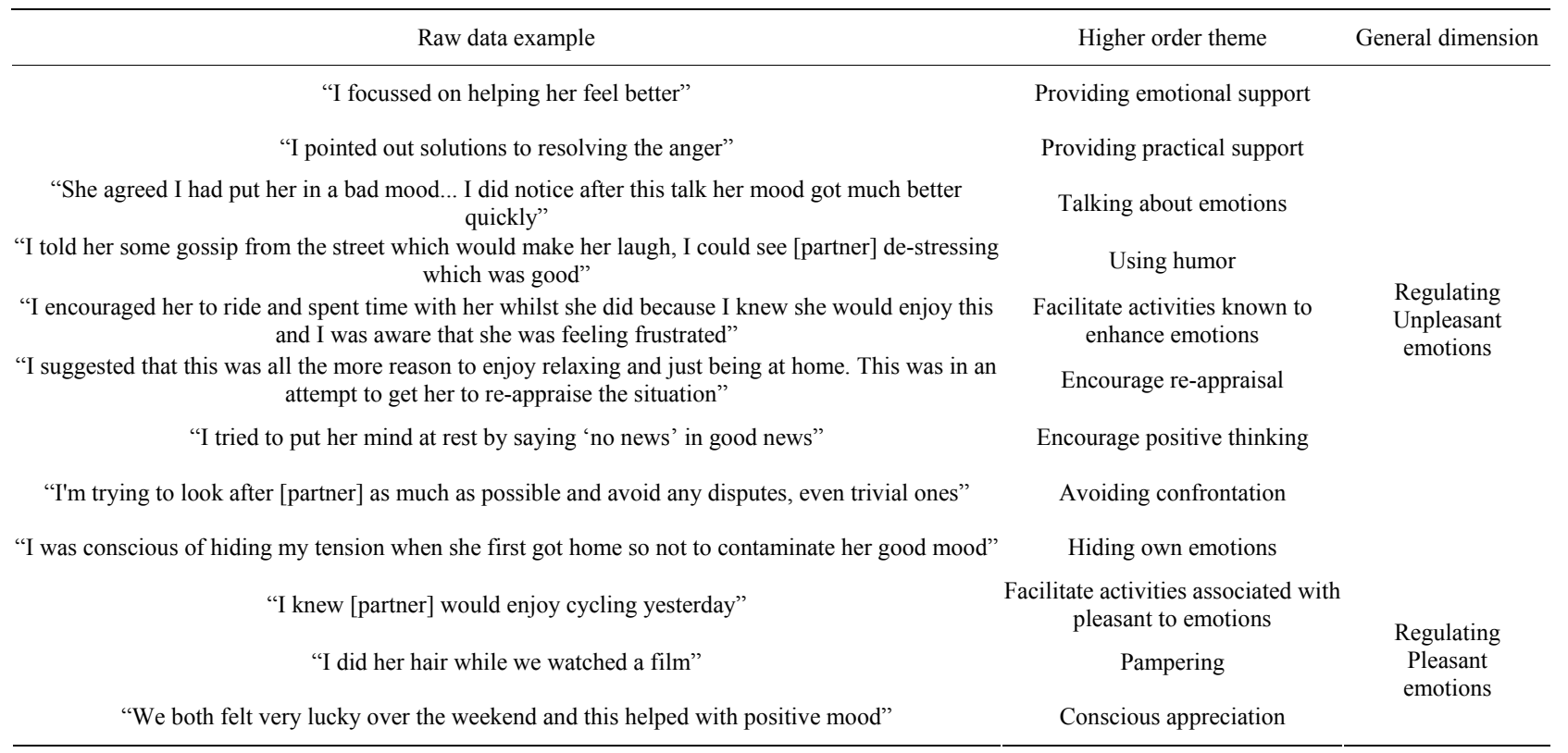


positive. I'm inclined to think positive until I know otherwise but it's easy for me to say that when it's not me having the treatment. [Partner] was very tearful most of the night and was probably wondering why I wasn't equally upset. I just continued to try and take her mind off things.

The first excerpt highlights the conscious use of strategies relative to partner preferences, whereas in the second example, there was a clear lack of control over treatment outcome. As such, the inter-personal strategies selected were to encourage positive thinking, comforting and the use of distraction from the stressors.

An observation made by participants regarding the recognition and regulation of emotions was that the process maintaining a daily mood diary increased awareness of actions and consequences. It also facilitated the early recognition of emotional changes and timely regulatory efforts to maintain desired states. These consequences are evidenced in the following excerpts:

Partner 1: This questionnaire makes me very mindful of what I' $m$ writing but also mindful of my actions throughout the day. I think this is a good thing because I can be selfish and fail to contemplate other people's perspective on things until it's too late.

Partner 2: Today and yesterday afternoon was most definitely my most difficult day in terms of sadness, worry and anxiety. Completing this diary has made this more overt and as such I have acted more quickly at times to try and manage these moods.

These findings highlight the potential benefits of daily mood diaries for participants.

\section{Discussion}

The present study explored stressors, emotional responses and emotion regulatory strategies used in relation to partner and self in a lesbian couple undergoing IVF. Both partners expressed a strong desire to have children and self-funded the relatively high treatment cost of IVF. In terms of the question, is one partner happier than the other? Quantitative results indicated no significant differences between emotion data. Previous research has found that women undergoing IVF experience intense unwanted emotions (Peddie et al., 2005; Van den Broeck et al., 2009). A possible explanation for this result is that partners in the present study did not find IVF to be a stressful experience. However, daily-diary results indicated both partners experienced frequent stressors stemming from interactions with medical staff, the course of treatment and the communication of information. As Table 3 indicates, stressors were clustered into three broad categories of hospital, tangible and perceptual stressors. The illustrative quotes provided demonstrate how the clear and highly meaningful personal goal of having children impacted upon participants stress appraisal, emotions and subsequent coping processes (Carver, 2004; Lazarus, 1999). Participants monitored events in relation to this goal, and experienced unpleasant emotions such as worry or anxiety, a finding consistent with notion that stress and emotion are inextricably linked (Lazarus, 1999, 2000). Consistent with the findings of Parkinson and Simons (2012) data indicate that by expressing worry or anxiety the individuals partner was alerted to a potential concern and this prompted the provision of emotional support. Participants engaged in a great deal of emotion regulation intended to increase pleasant emotions (Niven et al., 2009), hence suggesting that regulation strategies were implemented relatively early in the process (Webb, Miles et al., 2012), otherwise intense unpleasant emotions would be evident.

Consistent with previous research, both participants perceived a lack of control regarding aspects of IVF treatment (e.g., support offered by the hospital, responses to treatment). This perceived lack of control was found to be an antecedent of increased stress levels and intense unpleasant emotions (Jerusalem \& Schwarzer, 1992; Terry \& Hynes, 1998). For example, participants perceived the treatment schedule to be unclear in terms of what medication to take, when to take it, and for how long, even though the importance of adhering to the schedule was emphasized by medical staff. This uncertainty and associated consequences produced a high degree of threat along with a reduced sense of control (Lazarus \& Folkman, 1984; Mendes, Blascovich, Hunter, Lickel, \& Jost, 2007). This resulted in a corresponding increase in unpleasant emotions, particularly anxiety and anger, hence indicators of the unpleasant emotions reported in previous literature (Peddie et al., 2005; Van den Broeck et al., 2009). When participants were unable to clarify the treatment schedule, they used strategies including avoidance, distraction and positive thinking to regulate these unpleasant emotions. However, in this instance, hospital staff might have engendered greater perceptions of control by clarifying the treatment plan from the outset and explaining where deviations in treatment might occur (e.g., as a result of responses to treatment). In turn, this might have alleviated some of the stressors and unpleasant emotions perceived by both participants. Increasing control where possible, and enhancing the ability to regulate emotions where there is, and more importantly is not control over events, might prevent or reduce stress and help regulate unpleasant emotions.

In contrast to the daily diary data that clearly evidenced stressors and unpleasant emotions, questionnaire data indicated that participants reported feeling pleasant emotion states during the treatment process. Reconciliation of these results is explained by daily diary data that show each participant used reappraisal strategies, which have been found to regulate emotions before they intensify (Gross \& Thompson, 2007; Webb, Miles et al., 2012; Webb, Schweiger et al., 2012). Having explored some of the key stress perceptions and associated emotions, the questionnaire data allows an examination of emotional states and the influence of detection errors on strategies used to regulate emotion (Niven et al., 2009, 2011).

Questionnaire results demonstrate both partners made estimation errors in rating their partner's emotion. As Table 1 shows, partner 1 tended to over-estimate her partner's pleasant emotions, whereas partner 2 under-estimated her partner's pleasant emotions. Previous research has found evidence for individual differences in the ability to detect emotions in others (Petrides et al., 2009). Table 2 indicates that in both partners, the relationship between their own emotion and the perceived emotion of their partner correlated positively; in short, they indicated that if I feel happy, then I believe you do also. However, it is worth examining this relationship alongside the direction error.

Partner 1 perceived her partner to be feeling in a more pleasant emotional state than her own self-rating, however correlation results indicate that it was her own emotions which correlated to usage of regulation strategies, rather than her partners. Partner 1 tended to use regulation strategies to increase the intensity of her own and partners' pleasant emotions when she felt in a pleasant emotional state; the happier she felt, the 
more she used strategies to increase pleasant emotions in herself and her partner (Niven et al., 2012). These strategies used to maintain her own and partner's pleasant emotion are desirable for the couple because partner 1 seeks to maintain pleasant emotions where pleasant emotions are present. In contrast, partner 2 reported using strategies to increase her own emotion and her partner's emotions when she felt in an unpleasant emotional state or perceived unpleasant emotional state in her partner. When these results are seen in the context of a dyadic relationship, partner 2, uses emotion regulation strategies to increase pleasant emotions when unpleasant emotions are detected, whereas partner 1 seeks to maintain pleasant emotional states. Thus, the interaction between emotions and emotion regulation strategies used were complementary, and reduced the likelihood of either partner sustaining an unpleasant emotion. We propose that examining the combination of emotion and emotion regulation profiles in dyadic relationships will contribute to a better understanding of inter-personal and intra-personal emotion regulation. In doing so, it may be possible to predict where dyadic emotion regulation may be effective and ineffective relative to the attainment of desired emotional states. It may then be possible to propose suitable interventions to enhance dyadic emotion regulation.

Qualitative data indicate that an apparent perception underpinning many of the strategies identified for regulating own and others emotions was a perceived lack of control over events (see Tables 3-5). This was evident not only by explicit reference to a lack of control, but also by the strategies identified for emotion regulation. Intra-personal emotion regulation strategies were clustered under three broad categories of cognitive, behavioral and social strategies. Within the specific strategies identified there was a dominance of strategies focused on distraction, avoidance, and positive thinking (see Tables 4 and 5). Such strategies are focused on creating psychological distance from the stressor or managing the appraisal of events rather than addressing the circumstances producing the emotions. In accordance with previous literature, this would seem suitable for stressors perceived to be beyond control (Lazarus, 1999, 2000). Inter-personal regulatory strategies also demonstrated an alignment with a perceived lack of control but, in addition, appeared to take into conscious consideration partner's preferences for emotion regulation.

We contend that the mixed method daily diary design offers a strength within the present study as it facilitates a comprehensive and timely collection of data pertaining to those stressors, emotions and regulatory strategies associated with IVF treatment. The quantity and quality of data captured within this case study design might not be possible within large sample crosssectional studies. When exploring intra-personal and inter-personal emotion regulation, a mixed-methods approach enabled meaningful conclusions to be drawn from the data. Although quantitative data evidenced the use of strategies intended to regulate pleasant emotions experienced by self and partner, qualitative data indicated that this regulation occurred in the early stages of emotion detection. The conscious monitoring of emotion and associated regulation required in order to record daily emotion diary entries appeared to facilitate the early recognition and regulation of unpleasant emotions thereby preventing these emotions from intensifying further or enduring for longer. It appears that writing about stressful or emotional events not only helped to acknowledge the associated emotions (Baikie \& Wilhelm, 2005; Pennebaker \& Francis, 1996), but also enabled an understanding of the events and the associated requirements for emotion regulation, thereby lessening inhibition and rumination (Pennebaker, 1985).

The effective regulation of unpleasant emotions is described in the quantitative and qualitative data. Quantitative data indicates that both partners maintained a relatively pleasant emotional state during the treatment process and as such unpleasant emotions must have been transient. Qualitative data clearly identifies a plethora of strategies intended to regulate emotions, and offers an indication of the efficacy of these in the qualitative excerpts and tables (3-5) provided. Based on these findings, we contend that the process of maintaining a daily emotion diary, which should prompt reflection, in itself offers an intervention that might be utilized to enhance emotion awareness and regulation during IVF treatments, or indeed any emotive event (Frattaroli, 2006; Pennebaker, Colder, \& Sharp, 1990).

A limitation of present study is the generalizability of findings. We acknowledge that the use of a participant researcher may be perceived as both a desirable and undesirable aspect of the method. Both partners were motivated to provide honest and open accounts of the IVF experience. However, it might be perceived as a limitation because it may be suggested that the participant-researcher is unconsciously reinforcing her own bias in the interpretation of data. Attempts were made to minimize this limitation by adhering to guidelines advocated when undertaking researcher self-enquiry (Denzin, 1997; Denzin \& Lincoln, 2005). This included the second author taking the lead in data interpretation.

In conclusion, the present study harnessed the advantages offered by a mixed methods case study design to capture stress perceptions, emotions and emotion regulation of self and partner prior to, during and post IVF treatment in a female couple. The rich data highlighted the emotive nature of fertility treatments largely resulting from the importance of the goal to produce children and the lack of control over treatment outcomes. In a seemingly novel contribution to the emotion regulation literature, this study demonstrated that perceptual errors from both participants regarding their partner's emotions may have inadvertently contributed to the successful management of unpleasant emotions. Partner 2 underestimated partner 1's pleasant emotions, whilst partner 1 overestimated partner 2's pleasant emotions. The regulatory disposition of partner 1 was to use strategies intended to maintain pleasant emotions. Partner 2 was disposed to eliminate or attenuate unpleasant emotions. These regulatory dispositions therefore appear to complement one another and we would argue contribute to the successful regulation of emotions experienced to a more desired state.

Based on the findings presented we offer the following recommendations for practitioners. First, health care providers engaging in direct contact with recipients of assisted conception treatments should endeavour to keep patients informed of the treatment plan and changes to the schedule. Frequent opportunities should be presented for patients to seek clarification and reassurance. We propose that such actions might help patients gain greater clarity regarding treatment and more confidence in their control of known stressors. Second, in order to assist patients in managing treatment stressors and resultant emotions, patients should be appropriately counselled and informational resources provided on strategies associated with the effective regulation of stressors and unpleasant emotions. As evidenced in the present study, daily emotion diaries might in themselves present an emotion regulation intervention to those undertaking 
assisted conception treatments. This might help raise awareness of unpleasant emotions and the efficacy of strategies intended to regulate them. In conjunction with the counselling and provision of informational resources, this might further enhance patients' confidence in their ability to manage treatment stressors and resultant emotions. In doing so, should the treatment be unsuccessful, the individuals concerned might be more inclined to engage in further treatments. This is important as research indicates that many individuals choose to cease fertility treatments after a single failed attempt (Peddie et al., 2005).

\section{Acknowledgements}

The support of the Economic and Social Research Council (ESRC) UK is gratefully acknowledged (RES-060-25-0044: "Emotion regulation of others and self [EROS])".

\section{REFERENCES}

Augustine, A. A., \& Hemenover, S. H. (2008). On the relative effectiveness of affect regulation strategies: A meta-analysis. Cognition \& Emotion, 23, 1181-1220. doi:10.1080/02699930802396556

Baikie, K., \& Wilhelm, K. (2005). Emotional and physical health benefits of expressive writing. Advances in Psychiatric Treatment, 11, 338-346. doi:10.1192/apt.11.5.338

Bird, T., Mansell, W., \& Tai, S. (2009). Method of Levels: Initial steps in assessing adherence and the development of a qualitative framework for mapping clients' control hierarchies. The Cognitive Behaviour Therapist, 2, 145-166. doi:10.1017/S1754470X09990158

Boivin, J., \& Lancastle, D. (2009). Medical waiting periods: Imminence, emotions and coping. Women's Health, 6, 59-69. doi: $10.2217 /$ whe.09.79

Brunner, J. (2004). Life as narrative. Social Research, 71, 691-710.

Carver, C. S. (2004). Self-regulation of action and affect. In R. F. Baumeister, \& K. D. Vohs (Eds.), Handbook of self-regulation: Research, theory and applications (pp. 13-39). New York, NY: Guilford Press.

Consedine, N. S., \& Moskowitz, J. T. (2007). The role of discrete emotions in health outcomes: A critical review. Applied and Preventive Psychology, 12, 59-75. doi:10.1016/j.appsy.2007.09.001

Denzin, N. K. (1989). Interpretive biography. Newbury Park, CA: Sage.

Denzin, N. K., \& Lincoln, Y. S. (Eds.) (2005). The sage handbook of qualitative research (2nd ed.). Thousand Oaks, CA: Sage.

Eisenberg, N., Fabes, R. A., Guthrie, I. K., \& Reiser, M. (2000). Dispositional emotionality and regulation: Their role in predicting quality of social functioning. Journal of Personality and Social Psychology, 78, 136-157. doi:10.1037/0022-3514.78.1.136

Flyvbjerg, B. (2006). Five misunderstandings about case-study research. Qualitative Inquiry, 12, 219-245. doi:10.1177/1077800405284363

Frattaroli, J. (2006). Experimental disclosure and its moderators: A meta-analysis. Psychological Bulletin, 132, 823-865. doi:10.1037/0033-2909.132.6.823

Gross, J. J., \& John, O. P. (2003). Individual differences in two emotion regulation processes: Implications for affect, relationships, and wellbeing. Journal of Personality and Social Psychology, 85, 348-362. doi:10.1037/0022-3514.85.2.348

Gross, J. J., \& Thompson, R. A. (2007). Emotion regulation: Conceptual foundations. In J. J. Gross (Ed.), Handbook of emotion regulation (pp. 3-26). New York: Guilford.

Hayler, M. (2011). Autoethnography self-narrative and teacher education. Boston: Sense Publishers. doi:10.1007/978-94-6091-672-4

Higginson, S., \& Mansell, W. (2008). What is the mechanism of psychological change? A qualitative analysis of six individuals who experienced personal change and recovery. Psychology and Psychotherapy: Theory, Research and Practice, 81, 309-328. doi:10.1348/147608308X320125

Human Fertilisation and Embryology Authority (2012). IVF figures. http://www.hfea.gov.uk/ivf-figures-2006.html
Jerusalem, M., \& Schwarzer, R. (1992). Self-efficacy as a resource factor in stress appraisal processes. In R. Schwarzer (Ed.), Self-efficacy: Thought control of action (pp. 195-213). Washington DC: Hemisphere.

Lane, A. M., Beedie, C. J., Devonport, T. J., \& Stanley, D. M. (2011). Validity of the emotion regulation of self scale among in runners. Psychology, 2.

Lazarus, R. S. (1999). Stress and emotion: A new synthesis. New York: Springer.

Lazarus, R. S. (2000). Cognitive-motivational-relational theory of emotion. In Emotions in sport (pp. 39-63). United States: Human Kinetics.

Lazarus, R. S., \& Folkman, S. (1984) Stress, appraisal, and coping. New York: Springer.

Lazarus, R. S., \& Lazarus, B. N. (2006). Coping with aging. New York: Oxford University Press.

Liu, Y., Prati, L. M., Perrewé, P. L., \& Brymer, R. A. (2010). Individual differences in emotion regulation, emotional experiences at work, and work-related outcomes: A two-study investigation. Journal of Applied Social Psychology, 40, 1515-1538. doi:10.1111/j.1559-1816.2010.00627.x

Lucal, B. (1999). What it means to be gendered me: Life on the boundaries of a dichotomous gender system. Gender and Society, 13, 781797. doi:10.1177/089124399013006006

Macklon, N. S., Stouffer, R. L., Giudice, L. C., \& Fauser, B. C. (2006). The science behind 25 years of ovarian stimulation for in vitro fertilization. Endocrine Review, 27, 170-207. doi:10.1210/er.2005-0015

Matthews, G., Jones, D. M., \& Chamberlain, A. G. (1990). Refining the measurement of mood: The UWIST mood adjective checklist. British Journal of Psychology, 81, 17-42. doi:10.1111/j.2044-8295.1990.tb02343.x

Mendes, W. B., Blascovich, J., Hunter, S. B., Lickel, B., \& Jost, J. T. (2007). Threatened by the unexpected: Physiological responses during social interactions with expectancy-violating partners. Journal of Personality and Social Psychology, 92, 698-716. doi:10.1037/0022-3514.92.4.698

Niven, K., Totterdell, P., \& Holman, D. (2009). A classification of controlled interpersonal affect regulation strategies. Emotion, 9, 498. doi:10.1037/a0015962

Niven, K., Totterdell, P. A., Stride, C., \& Holman, D. (2011). Emotion Regulation of Others and Self (EROS): The development and validation of a new measure. Current Psychology, 30, 53-73. doi:10.1007/s12144-011-9099-9

Niven, K., Totterdell, P., Holman, D., \& Headley, T. (2012). Does regulating others' feelings influence people's own affective wellbeing? The Journal of Social Psychology, 152, 246-260. doi: $10.1080 / 00224545.2011 .599823$

Olivius, C., Friden, B., Borg, G., \& Bergh, C. (2004). Why do couples discontinue in vitro fertilization treatment? A cohort study. Fertility and Sterilility, 81, 258-261. doi:10.1016/j.fertnstert.2003.06.029

Parkinson, B., \& Simons, G. (2012), Worry spreads: Interpersonal transfer of problem-related anxiety, Cognition and Emotion, 26, 462479. doi:10.1080/02699931.2011.651101

Peddie, V. L., Van Teijlingen, E., \& Bhattacharya, S. (2005). A qualitative study of women's decision-making at the end of IVF treatment. Human Reproduction, 20, 1944-1951. doi:10.1093/humrep/deh857

Pennebaker, J. W. (1985). Traumatic experience and psychosomatic disease. Exploring the roles of behavioural inhibition, obsession, and confiding. Canadian Psychology, 26, 82-95. doi:10.1037/h0080025

Pennebaker, J. W., Colder, M., \& Sharp, L. K. (1990). Accelerating the coping process. Journal of Personality and Social Psychology, 58, 528-537. doi:10.1037/0022-3514.58.3.528

Pennebaker, J. W., \& Francis, M. E. (1996). Cognitive, emotional, and language processes in disclosure. Cognition and Emotion, 10, 601626. doi:10.1080/026999396380079

Petrides, K. V., Furnham, A., \& Mavroveli, S. (2007). Trait emotional intelligence: Moving forward in the field of EI. In G. Matthews, M. Zeidner, \& R. Roberts (Eds.), Emotional intelligence: Knowns and unknowns. Oxford: Oxford University Press.

QSR NVIVO-8 (2009). Computer software. Thousand Oaks, CA: Sage. 


\section{T. J. DEVONPORT, A. M. LANE}

Sandelowski, M. J. (1994). We are the stories we tell: Narrative knowing in nursing practice. Journal of Holistic Nursing, 12, 23-33. doi: $10.1177 / 089801019401200105$

Schmidt, L. (2009). Social and psychological consequences of infertiliity and assisted reproduction-what are the research priorities? Human Fertility, 12, 14-20. doi:10.1080/14647270802331487

Sheppes, G., Scheibe, S., Suri, G., \& Gross, J. J. (2011). Emotionregulation choice. Psychological Science, 22, 1391-1396. doi: $10.1177 / 0956797611418350$

Stake, R. E. (1995). The art of case study research. Thousand Oaks, CA: Sage.

Tabachnick, B. G., \& Fidell, L. S. (2001). Using multivariate statistics. New York: Harper Collins.

Tamir, M. (2011). The maturing field of emotion regulation. Emotion Review, 3, 3-7. doi:10.1177/1754073910388685

Terry, D. J., \& Hynes, G. J. (1998). Adjustment to a low control situation: Re-examining the role of coping responses. Journal of Personality and Social Psychology, 74, 1078-1092. doi:10.1037/0022-3514.74.4.1078

Totterdell, P., Hershcovis, M. S., Niven, K., Reich, T. C., \& Stride, C. (2012). Can employees be emotionally drained by witnessing unpleasant interactions between coworkers? A diary study of induced emotion regulation. Work \& Stress, 26, 112-129. doi: $10.1080 / 02678373.2012 .681153$

Van den Broeck, U., Holvoet, L., Enzlin, P., Bakelants, E., Demyttenaere, K., \& D'Hooghe, T. (2009). Reasons for dropout in infertili- ity treatment. Gynecologic and Obstetric Investigation, 68, 58-64. doi:10.1159/000214839

Verberg, M. F. G., Eijkemans, M. J. C., Heijnen, E. M. E. W., Broekmans, F. J., de Klerk, C., Fauser, B. C. J. M., \& Macklon, N. S (2008). Why do couples drop-out from IVF treatment? A prospective cohort study. Human Reproduction, 23, 2050-2055. doi:10.1093/humrep/den219

Verhaak, C. M., Smeenk, J. M. J., Evers, A. W. M., Kremer, J. A. M., Kraaimaat, F. W., \& Braat, D. D. M. (2007). Women's emotional adjustment to IVF: A systematic review of 25 years of research. Human Reproduction Update, 13, 27-36. doi:10.1093/humupd/dml040

Walsh, A. P. H., Collins, G. S., Le Du, M., Walsh, D. J., \& Sills, E. S. (2009). Pre-treatment preferences and characteristics among patients seeking in vitro fertilisation. Reproductive Health, 6, 21. doi:10.1186/1742-4755-6-21

Webb, T. L., Schweiger Gallo, I., Miles, E., Gollwitzer, P. M., \& Sheeran, P. (2012). Effective regulation of affect: An action control perspective on emotion regulation. European Review of Social Psychology, 23, 143-186. doi:10.1080/10463283.2012.718134

Webb, T. L., Miles, E., \& Sheeran, P. (2012). Dealing with feeling: A meta-analysis of the effectiveness of strategies derived from the process model of emotion regulation. Psychological Bulletin, 138, 775808. doi: $10.1037 / \mathrm{a} 0027600$ 